\title{
ESSAY
}

\section{Empowering Citizens to Inform Decision-Making as a Way Forward to Support Invasive Alien Species Policy}

\author{
Quentin Groom*, Diederik Strubbe ${ }^{\dagger}$, Tim Adriaens, Amy J. S. Davis ${ }^{\dagger}$, Peter Desmet ${ }^{\ddagger}$, \\ Damiano Oldoni ${ }^{\ddagger}$, Lien Reyserhove ${ }^{\ddagger}$, Helen E. Roy ${ }^{\S}$ and Sonia Vanderhoeven $\|$
}

\begin{abstract}
Observations reported by citizens are crucial to the ability of scientists to inform policy on biodiversity. This is particularly relevant in the case of preventing and controlling biological invasions; that is, the introduction and spread of species outside their natural ranges as a consequence of human activity. Such invasions of natural ecosystems represent one of the main threats to biodiversity, economy, and human well-being globally, and policies on tackling this issue require a strong evidence base that increasingly is built on citizen science. Many citizens are motivated to collect data for their own interest, while presumably, few expect to make a major impact on policy. The needs of policy-makers are not always aligned with the approaches used by citizens to collect and share data. Therefore, how can we motivate citizen science for the needs of policy without compromising the enjoyment that citizens gain from collecting biodiversity observations? How can policy-makers support citizens to collect the data they need?

Solutions require two components, a combination of social and technological innovation. Initiatives aimed at supporting decision-making processes should involve more societal actors and be built in a more collaborative or even co-created manner with citizens, scientists, and policy-makers. Technological solutions can be achieved through regular, rapid, and open publication of biodiversity data products. We envisage frequent publication of maps and indicators from rapidly mobilized data, with clear pointers to gaps in knowledge. Improving the links between data collection and delivery of policy-relevant information demonstrates - to citizens and their organizations - the need for their data, and gives them a clear view on the impact of their data on policy. This visibility also empowers stakeholder organizations in the policy development process.
\end{abstract}

Keywords: data workflow; democratization; biodiversity; volunteer; sustainability; motivation

\section{Citizen Science and Biological Invasions}

Humans have always transported species beyond their natural ranges, either intentionally (e.g., for agriculture and hunting) or unintentionally (e.g., in ship ballast) (Essl et al. 2015). Largely driven by the growth of global trade, the number of introduced species does not show any sign of saturation and for most taxa, introduction rates are increasing (Seebens et al. 2017). Specific policies, such as tighter biosecurity regulations and increased invasion awareness, can be successful in curbing this trend. For example, New Zealand's 1993 Biosecurity Act means that before importing species into the country, a full risk assessment must be conducted for all species, except for those mentioned on a white-list of permitted species. This

\footnotetext{
* Meise Botanic Garden, BE

Ghent University, BE

Fesearch Institute for Nature and Forest (INBO), BE

Centre for Ecology and Hydrology, Wallingford, GB

\| Belgian Biodiversity Platform, BE

Corresponding author: Quentin Groom

(quentin.groom@plantentuinmeise.be)
}

stringent law is the presumed cause of decreasing first record rates of introduced vascular plant species, bucking general trends (Seebens et al. 2017). Expanding trade networks, coupled with global environmental change, result in the opening of new reservoirs of potentially invasive species. This suggests that a high proportion of emerging alien species remains to be encountered (Essl et al. 2010). This is problematic, because invasive alien species rank fifth among the main threats to biodiversity, economy, and human well-being globally (IPBES 2019). For example, introduced predators such as rats, cats, and snakes are a leading cause of bird extinctions, especially on remote islands with high degrees of endemism (Clavero et al. 2009). However, Bellard, Cassey, and Blackburn (2016) also showed that invasive alien species are a significant concern for mainland species currently threatened with extinction; they are implicated in 14\% of alien-species related extinctions of plants, amphibians, reptiles, birds, and mammals worldwide. Bradshaw et al. (2016) report that introduced insects alone cost a minimum of US $\$ 70$ billion in damages per year globally, and this likely is an underestimate. Invasive species can also directly imperil 
human health and well-being, for example, the spread of North American Ambrosia artemisiifolia across Europe led to an increase in the duration and intensity of the hay fever season (Smith et al. 2013). Pratt et al. (2017) report impacts of invasive species on livelihoods through negative effects on farm production and food security, especially in developing countries; there are numerous examples of such invasions across taxa and economic sectors (e.g., Smith and Tibbles 1980; Knowler 2005).

Tackling invasive species necessitates proactive management strategies, because eradicating invasive alien species is often difficult and costly (Myers et al. 2000). Strictly regulating - or even banning - the trade of species that are highly likely to become invasive, coupled with early warning and rapid response systems, are generally regarded as the most effective management strategy (Leung et al. 2002). This approach, however, requires timely detection of establishing invaders through monitoring schemes. For example, pheromone traps deployed at points of entry detect unintentional introductions of devastating insect pests, such as the western corn rootworm Diabrotica virgifera, a quarantine organism that costs Europe around 147 million euros a year (Augustin et al. 2012). Yet, given the large number of potentially invasive species and large geographical areas at risk (e.g., ports, waterways, road networks), such dedicated monitoring schemes are feasible only for specific species in high-risk locations. In addition, such schemes often need to be informed by specific knowledge on pathways of introduction and commodities in which invasive species arrive.

The issue of biological invasions has a close link to science and decision-making. Science describes the phenomenon, attempts to understand the invasion processes, anticipates potential adverse impacts, and investigates the effectiveness of management options, from prevention to species management and the restoration of impacted ecosystems (Early et al. 2016; McGeoch et al. 2010; Simberloff, Parker, and Windle 2005). Sciencebased strategies to tackle invasive species involve horizon scanning, risk assessment and risk management, and targeted eradication and control actions. All of these activities are highly dependent on recent, accurate, welldocumented, standardized, and openly accessible information on alien species (Groom et al. 2015; Groom et al. 2017b; Schade et al. 2019). In the context of the European Union Regulation (Regulation 1143/2014) on invasive species, policy requires evidence-based answers to questions such as: Which species are potentially most harmful to the Union? Which species are on the horizon and which species are currently emerging? Are these species capable of reproducing in the wild and how will their distribution evolve under changing environmental conditions? What are their routes of introduction? The answers to these questions inform the decision-making processes that European Union Member States must put in place to respond to the European Regulation and create a List of Invasive Alien Species of Union Concern (Tollington et al. 2017; Vanderhoeven et al. 2015). The Union Concern species are those deemed to have potential adverse impacts across the European Union such that concerted action across Europe is required.
Observations from citizen scientists are crucial to our ability to inform policy on biodiversity conservation challenges, from the decisions made by government to those made by local conservation managers. This is particularly relevant in the case of controlling and preventing biological invasions (Chandler et al. 2017; Silvertown 2009; Theobald et al. 2015; Anderson et al. 2017). A wealth of species occurrence data generated by citizen scientists enables surveillance of emerging and established invaders at larger spatial extents. The potential of citizen science for passive risk-oriented surveillance has, for example, been shown in disease vector mapping for ticks and mosquitos (Palmer et al. 2017; Hamer, Curtis-Robles, and Hamer 2018). Given proper training, citizen scientists are able to detect and report invasive species, even if they are dangerous or difficult to identify, and the data they collect are used by professional scientists as well as management programmes (Gallo and Waitt 2011; Kampen et al. 2015; Wallace et al. 2016).

It is widely acknowledged that citizen science can play a significant role in public engagement, improved education, and awareness of environmental issues. This awareness is fundamental to attain the objectives of alien species policies (Caffrey et al. 2014). Involving citizens in decision-making on invasive alien species is especially crucial to reduce conflicts of interest and improve consensus regarding their management (Shackleton et al. 2019). Hence, the link between citizen science and invasive species is obvious. Numerous citizen science projects focused on alien species reflect the potential of citizen science for gathering data on alien species while ensuring effective and high-quality societal engagement. Moreover, the need for engagement is explicitly recognised in invasive species policies (Shackleton et al. 2019). The European Union Regulation refers to volunteer participation in decision-making (including citizen science, public awareness, and education) through engagement in surveillance and monitoring (Schade et al. 2019). More specifically, the Alien-CSI COST Action (CA17122) Increasing understanding of alien species through citizen science supported by COST (European Cooperation in Science and Technology) strives to strengthen the network of alien species citizen science projects to improve decision-making and to foster exchanges among citizens, scientists, managers, policymakers, local authorities, industry, and other stakeholders (Roy et al. 2018). At the global level, meta-networks are being set up which also aim to support and promote effective citizen science related initiatives on invasive species (Lucy et al. 2016).

One might question whether unpaid citizens can provide sufficiently accurate data for robust scientific analysis, yet the evidence suggests that this is the case (Crall et al. 2011; Grason et al. 2018). Professional scientists provide robust data, but the long time series and land coverage of citizens' observations can be leveraged to meet the demands of both policy and research (Giraud et al. 2016; Grason et al. 2018; Scyphers et al. 2015). For example, in recent policy reporting from Belgium on the baseline distributions of species on the European Union List of Concern, twothirds of the data used came from citizen science recording 
platforms (Adriaens et al. 2018; Tollington et al. 2017). The relationship among researchers, policy-makers, and citizen scientists could be more symbiotic, but often is not strong in practice. Some citizens are happy for their data to be used for policy, although this is mostly a secondary motivational factor that affected only their ongoing participation in citizen science projects, not their initial decision to participate in projects (Rotman et al. 2012).

Traditionally, species distributions have been communicated in atlases with a regional, national, or continental scope at irregular intervals, which may not be up-to-date. Amateur naturalists with or without collaborators in museums, local and national agencies, and academia often prepare these atlases after many years of data collection and as part of a wider biological recording community. For example, the Botanical Society of Britain and Ireland first published an atlas in 1962 (Perring and Walters 1962), published a second in 2000, and are currently working on a third. Evidently, these are important and worthy works for biogeographical research. In general, data collected by biological recorders working within atlas or monitoring scheme frameworks produce datasets that are highly valued by governments, scientists, and the volunteers themselves (Pescott et al. 2015), but they are not well aligned with reuse for policy, especially in the rapidly changing environment that we live in. Principally, they do not report rapidly enough to be practically useful in supporting decision-making on invasive alien species and species extinctions (Boakes et al. 2010; Dickinson, Zuckerberg, and Bonter 2010). Atlases are gradually being superseded by online sources of information, though fragmentation of the sources and openness of data are significant obstacles to capturing and understanding change (Wetzel et al. 2018; Groom, Weatherdon, and Geijzendorffer 2017).

Numerous models exist for citizen science funding, management, and structure. These reflect their aims, their funding streams, and their geographic scope, and strongly influence the availability and scientific value of the data they collect (Geldmann et al. 2016). Yet, policy-makers cannot dictate to volunteer citizen scientists the way that data are collected to make them useful to inform policy (Groom, Weatherdon, and Geijzendorffer 2017). Moreover, new models of citizen participation are emerging, such as those relying on mobile phone apps and camera traps (August et al. 2015).

Citizen scientists gain a great deal of personal satisfaction and pleasure from observing and studying wildlife. Some enjoy searching for rare creatures, while others are intrigued by the beauty and curiosity of nature. Making a meaningful contribution to nature conservation through collecting and sharing wildlife observations is an important motivation for many volunteers; this sustains their engagement (Geoghegan et al. 2016). However, volunteers' perspectives of nature conservation can be different from those of a policy-maker at a national, continental, or global level. The scale of concern for the environment is often quite different and sometimes conflicting. The management of invasive alien species is a particular cause of conflict in the field of biodiversity conservation, because perceptions of costs and benefits differ among stakeholders (e.g., Novoa et al. 2016). Informing policy and management planning is a strong motivator of stakeholder engagement in the study and management of invasive alien species, but engagement is still implemented in a top down fashion in invasion science (Shackleton et al. 2019). Scientists want data to push the boundaries of biodiversity knowledge. Wildlife managers want successful conservation outcomes, and policy-makers want reliable information that helps them make decisions. The duties of a policy-maker are not always compatible with satisfying the expectations of citizen scientists and professional scientists, as decisions are also made with broader socioeconomic considerations. There are also concerns about the reliability and function of citizen science, including the impact on the integrity of science, intellectual property, and the image of science that is being conveyed to citizens (Guerrini et al. 2018; Baghramian et al. 2019).

Can the activities of citizens, scientists, managers, and policy-makers be more synergistic and mutually understanding? After all, many people participate as volunteers, professionals, and policy-makers, either in different capacities or at different times in their career. Can we motivate citizen science for these needs without losing the interest, pleasure, and fascination that citizens gain from collecting biodiversity observations?

\section{Towards Solutions}

A set of complementary options can be combined to empower citizen science to inform decision-making. This set has two components, being a combination of social and technological innovation.

From a societal perspective, citizen involvement does not rely only on the basic assumptions of an additive effect: More observers, more data. Indeed, psychological studies have provided evidence for collective intelligence in the performance of human groups (Woolley et al. 2010), providing an argument for designing citizen science projects according to different types of voluntary engagement (Bonney et al. 2009; Pocock et al. 2015; Senabre, Ferran-Ferrer, and Perelló 2018). Projects can be broadly classified into either contributory, collaborative, or cocreated projects (Shirk et al. 2012). Participants involved in contributory projects mainly take part in data gathering. Collaborative projects increase participants' potential for action by also inviting them to design studies, analyse samples, interpret data and draw conclusions. Societal involvement is maximized in co-created projects, in which participants collaborate in all stages of the project, including defining issues, developing hypotheses, discussing results, and developing policy recommendations. Collaborative and co-created approaches would be expected to show considerable potential for achieving common conservation goals (Dickinson et al. 2012), assuming that project initiators and decision-makers move away from the traditional top-down way of working. This is particularly challenging, because it means that the citizens contribute to identifying questions themselves, such that policy-makers and scientists must relinquish some control (Dickinson et al. 2012). This will contribute to greater democratisation of biodiversity science (Irwin 2001). 
The solution - from a technical perspective - is to create tighter links between the generation of data, the knowledge derived from it, and decision-making. This is achieved through the establishment of repeatable workflows built on open science, using common infrastructures and based on solid communication strategies to volunteers. Open data and open results are part of the solution because they solve a major hurdle to interoperability (Adriaens et al. 2015; Groom et al. 2017b; Robertson et al. 2014). In the absence of open data, users need to track multiple data use agreements in all downstream products of an aggregate dataset. This is time-consuming, impractical, and would inevitably lead to compromises either in the results or would limit the questions that could be addressed. When open data are accompanied by commonly agreed data standards and provided with complete metadata, they provide a solid foundation for data products that conform to the FAIR Data Principles, providing scientific reproducibility, verifiability, citability, and attribution (Wilkinson et al. 2016). In addition, sharing the methodology, including programming code that is used to create downstream products, such as indicators and trends, supports reproducibility (Easterbrook 2014) and the adoption of an accepted framework to provide verifiable information to policy. It also reduces costs by avoiding duplication of effort (Stodden, Guo, and Ma 2013; Jarnevich et al. 2015). The infrastructures to support open data are common standards for data exchange, including data models, controlled vocabularies, and shared consensus taxonomies. Open application programming interfaces provide these data, while globally unique persistent identifiers link these data together and allow seamless navigation across linked datasets (Page 2016).

The need for seamless workflows is also driven by the evidence that feedback and communication to volunteers are two of the most important motivators of continued activity in citizen science projects (Ferreira, Proenca, and Proenca 2009; Geoghegan et al. 2016). Frequent sharing of maps and other readily interpretable visualizations alongside well-defined indicators from rapidly mobilized data should be envisaged to report on the extent of biodiversity change, with clear pointers to uncertainty and where gaps in knowledge exist. This would provide improved links between data collection and policy, demonstrate to citizens and their organizations the need for their data, and give them incentive to collect, improve quality, and potentially focus their data collection on undersampled areas and taxa. It also is a means by which citizens, researchers, and policy-makers can potentially evaluate the impact of policy decisions.

Slow mobilization of data and long lag times for feedback to citizen scientists could be resolved by regular and rapid processing. There is no technical reason why biodiversity indicators should not be output on a weekly or even a daily basis to provide instant feedback to data publishers, citizen scientists, and policy-makers. For many species, such rapid publication is perhaps unnecessary, yet it is particularly important to prevent the establishment of many invasive species (Genovesi and Shine 2004; Wittenberg and Cock 2001; Crall et al. 2012).
Many data are still housed locally or nationally, and are therefore inaccessible for international scientific analyses or policy making, while a collaborative international approach is needed for many data types. For example, it makes little sense for scientific names architecture to be housed nationally, with countries duplicating work many times over, yet this is currently the state of play. At a global level, the Global Biodiversity Information Facility (GBIF) is an important aggregator of biodiversity data linked to the implementation of invasive alien species policy (Katsanevakis et al. 2015), however, not all countries are members. There are many other organizations at the (supra)national level (Lucy et al. 2016) supporting similar approaches, and national policy-makers must evaluate which pieces of infrastructure are more suitable at a national level and which are best housed globally.

An example of a highly successful citizen science project that informs invasive species policy is the eBird observation network. Launched in 2002, it has rapidly become one of the world's most important sources of avian biodiversity data with more than 100 million bird sightings contributed each year (Sullivan et al 2014). One of the reasons for its success is that it facilitates what birders often care most about, alongside the actual motivation to see birds - namely entering, storing, and accumulating their observations (Lagoze 2014), but it combines bird listing with community building by appealing to both competitive and collaborative human instincts. For example, birders are motivated by contests such as the "checklist-a-day" challenge, whereby they can win prizes when submitting an average of at least one checklist per day. Regular events such "Global Big Day" invite birders to observe as many bird species as possible. For instance, on May $5^{\text {th }}, 2018$ no less than 28,000 birders contributed more than 1.6 million bird observations spanning 170 countries finding more than two-thirds of the world's bird species in a single day (eBird 2018). eBirds' website also allows for easy visualization of submitted observations, for example allowing tracking - in real time - of ongoing bird migration. This enables birders to gauge when a certain species will arrive in their area, creating a feedback loop whereby they venture outside to record and submit observations of migrating birds when they do arrive (Hurlbert and Liang 2012). eBird data already feature prominently in academic studies aimed at understanding and predicting introduced bird species invasion success and potential geographical spread (Cardador et al. 2016). Standardized eBird data are prominent on GBIF, directly accessible from research analysis software and hence are a prime source of occurrence data used for risk mapping and planning biosecurity surveillance for bird invaders (e.g., Vall-llosera et al. 2017).

\section{Putting the Solutions into Practise}

The Belgian Tracking Invasive Alien Species (TrIAS) project aims to create a cyclic workflow based upon some of these solutions and is described in Figure $\mathbf{1}$ (Vanderhoeven et al. 2017). The project was born out of a need for technical and communication tools to address policy questions on invasive species. The project relies on invasive alien spe- 


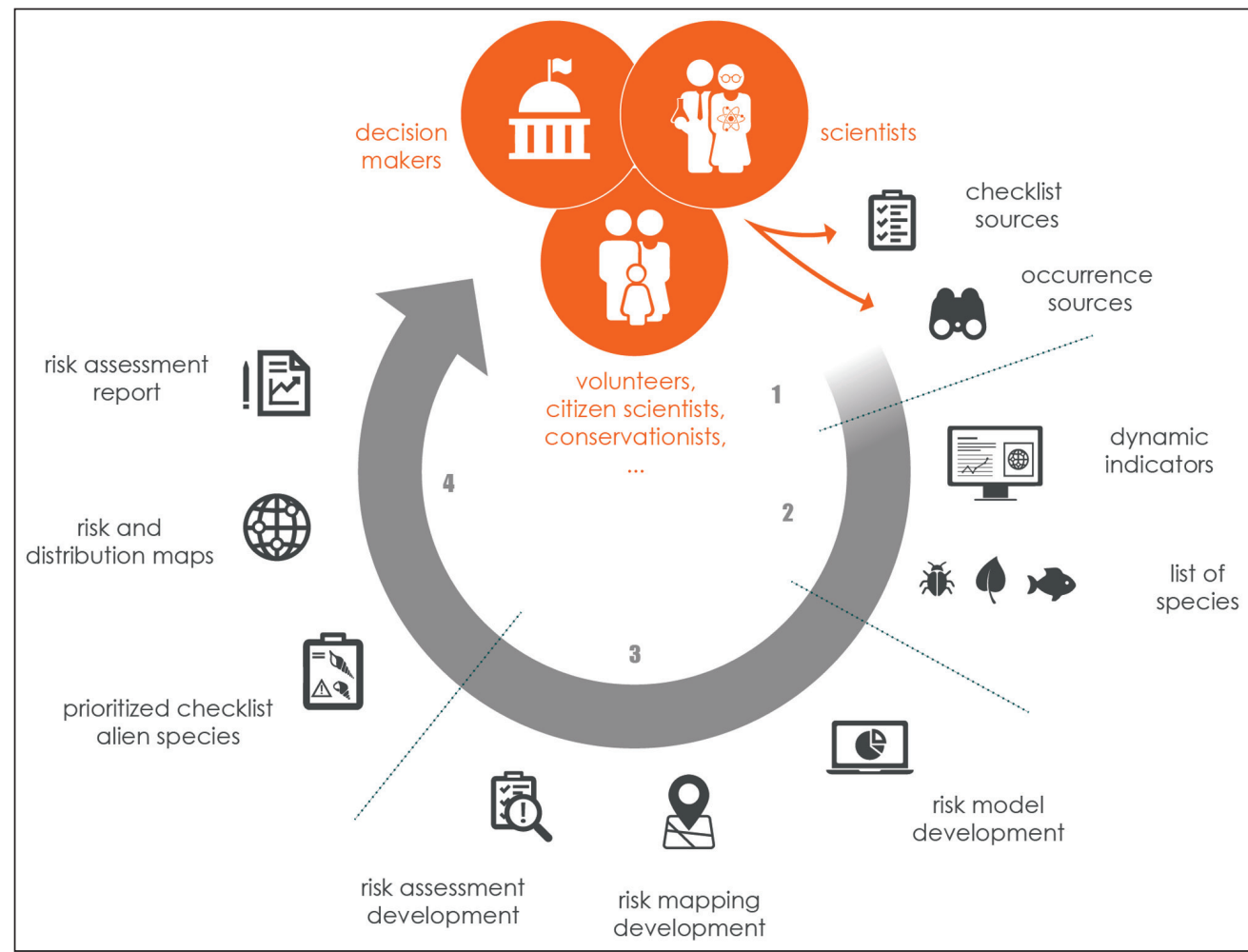

Figure 1: Citizens and biodiversity scientists both are providers of invasive species data and users of the information created from them. Open data workflows can be created whereby contributors of data produce the aggregated knowledge about the organisms that interest them. Products such as maps, indicators, and predictive models aim to support the data providers, while also creating policy relevant information. In the Belgian TrIAS project, a cycle is envisaged that starts with data publication and continues with the generation of aggregate indicators, maps, models, and risk assessments. All this analysis results in publications aimed both at the contributors of data and policy support. This motivates citizens and scientists alike and creates a cycle supporting knowledge creation. The participants contribute most to the information cycle, but because the data are openly licenced, information can be spun off for use in policy. However, policy-makers can contribute to this cycle in many ways, such as by sharing public data, by providing training, and by supporting the underlying infrastructures.

cies research, science policy, and citizen science initiatives. As the project proposes ...

"Imagine a future where dynamically, from year to year, we can track the progression of alien species, identify emerging problem species, assess their current and future risk and timely inform policy in a seamless data-driven workflow. One that is built on open science and open data infrastructures. By using international biodiversity standards and facilities, we would ensure interoperability, repeatability and sustainability. This would make the process adaptable to future requirements in an evolving alien species policy landscape both locally and internationally." (Vanderhoeven et al. 2017).

At the end of the project, all the developed tools and procedures will be an integral part of the Belgian decisionmaking process for invasive species and will be integrated into the Belgian information system Harmonia (D'hondt et al. 2015; Vanderhoeven et al. 2015).

The first step in TrIAS is creating open and sustainable data publishing pipelines for data from citizens and professional scientists (Figure 1, step 1). TrIAS uses GBIF as a central store and a resolver of data. TrIAS also mobilizes and publishes species checklists and occurrence data to GBIF. The link with GBIF offers reliability and sustainability, and imposes a degree of standardization on the data (Costello et al. 2013; Robertson et al. 2014), which facilitates data verification, i.e., the process of checking conformity with data standards. All the data are published openly, under standard licences, and are citable. This means that TrIAS results are verifiable and if other data are published to GBIF through other data providers, they also can be incorporated into the flow with minimal additional work. The reuse of GBIF infrastructure has other advantages that encourage data reuse. Each dataset is independently citable, so contributors can get credit for their contribution from many other projects in addition to TrIAS. Data publishers are responsible for data quality and data validation, making sure the data are correct and useful, and they have full control over the data they publish and the frequency at which they publish.

The next step of TrIAS is to harvest and aggregate occurrence data (Figure 1 step 2). Again, there are advantages of using GBIF, because programming interfaces and other tools are available to harvest data in a standard format. TrIAS is building this workflow using the open source software language $\mathrm{R}$, and all elements of the workflow are published using an open source licence on GitHub. This 
allows anyone to rerun these workflows or to adapt them for alternative uses. For example, an obvious reuse might be repeating the TrIAS workflow in a different country or region. Once data have been aggregated, indicators relevant to decision-making for invasive alien species policy and management are produced. They allow, for example, the feeding of indicators to evaluate the impact of policy decisions at country or regional level, the production of prioritized lists of emerging species for risk assessment, the identification of natural areas at risk, identifying alien species emerging in protected areas and the prioritization of introduction pathways for the establishment of national action plans to prevent invasions through pathway control. These indicators can either be produced on demand or on a regular basis. Furthermore, when analysis methods have been improved or new data have become available, the code can be updated and the workflow rerun. Step 3 is building risk models based on distribution data to make predictions related to environmental change, such as climate change, and to incorporate this information into species risk assessments. In step 4, the results are disseminated in a variety of formats, ready to use by the different stakeholders including citizen scientists, researchers, invasion managers, and policy-makers. The formats include distribution maps, prioritized lists of emerging species, invasion heat maps, and their associated uncertainty.

Although the TrIAS approach will help pave the way towards a faster, better, and stronger link between citizen science, research, and policy, currently citizen involvement in TrIAS is contributory and not collaborative or co-creative. However, the TrIAS workflow is adaptable: Rapid communication to citizens can influence their survey strategies, i.e., to focus on particular species or habitats, fill potential data gaps, and consequently improve invasive species policy. TrIAS lacks the involvement of citizens in project design and framing research questions. It is similar to many current science funding schemes that allow only few opportunities for real citizen involvement or co-creation (Figueiredo Nascimento et al. 2016).

\section{Recommendations}

Meeting the challenge of biodiversity conservation and making the most of citizen science potential requires a set of improvements from current practices. Based on our experience with the TrIAS framework, we recommend:

1. Use open by default for data, software, and communication. Without an open approach to sharing data none of the other recommendations are possible. This is fundamental to providing all the services to citizens, scientists, and decision-makers.

2. Support data infrastructure for biodiversity. Providing a financial and legal framework under which open informatics infrastructure can operate underpins national and international biodiversity data science.

3. Strengthen communication. The aims of biodiversity scientists, conservationists, and policy-makers need to be communicated clearly and regularly. Scientists should also seek innovative visualisations to attract citizen interest. Communication should also be ongoing and in both directions supporting a collaborative approach. For example, communication should be based on good case studies of citizen science.

4. Improve mutual understanding. Seek to increase the mutual understanding of the motivations of all players. This allows for the deeper engagement of the different parties, democratization of science, and increased ownership of the results.

5. Support citizen science globally. All countries should support citizen science, because biodiversity loss is a global issue and this is a cost-effective proven solution to gathering data.

\section{Conclusion}

In the case of biodiversity conservation around invasive alien species there is much to be gained for policymakers, researchers, and citizen scientists from a closer, more symbiotic relationship built on common goals and mutual understanding. We cannot claim to have the perfect solution to the problems we have outlined and undoubtedly solutions will depend on the political and social landscape. However, we do believe that information technology can be used to rapidly convert data into information and to converge the interests of citizens and policy. Tightening the links between the creation of data, the knowledge created from data, and decision-making will demonstrate to policy-makers the value of encouraging and supporting citizen science initiatives. Just as weather forecasters take data from multiple sources and provide information to numerous stakeholders, so we see the mobilization of biodiversity data in the future to support everyone who needs information about our biological environment.

\section{Acknowledgements}

We acknowledge Sven Bellanger for the design of the figure and the support of the Belgian Science Policy Office under the TrIAS project (BR/165/A1/TrIAS) and Alien-CSI COST Action (CA17122), supported by COST (European Cooperation in Science and Technology). Helen Roy was supported by the Natural Environment Research Council award number NE/R016429/1 as part of the UK-SCAPE programme delivering National Capability.

\section{Competing Interests}

The authors have no competing interests to declare.

\section{Author Contributions}

DS, QG, PD, TA, and SV came up with the original TrIAS concept. All authors have contributed to writing the paper and discussing the philosophy behind it in project meetings. AD, DO, LR, PD, SV, TA, and QG are actively implementing the TrIAS model and in doing so have contributed to the shaping of the concept. HR has in addition supported the paper by providing opportunities in workshops to discuss issues related to the paper. 


\section{References}

Adriaens, T, Groom, Q, Vanderhoeven, S, Davis, A, Strubbe, D, Reyserhove, L, Desmet, P, Oldoni, D and D'hondt, B. 2018. The importance of citizen science for research, policy and management on invasive alien species. Natuur.focus, 17(4): 185-193.

Adriaens, T, Sutton-Croft, M, Owen, K, Brosens, D, van Valkenburg, J, Kilbey, D, Groom, Q, Ehmig, C, Thürkow, F, Van Hende, P and Schneider, K. 2015. Trying to engage the crowd in recording invasive alien species in Europe: experiences from two smartphone applications in northwest Europe. Management of Biological Invasions, 6: 215-225. DOI: https://doi. org/10.3391/mbi.2015.6.2.12

Anderson, LG, Chapman, JK, Escontrela, D and Gough, CL. 2017. The role of conservation volunteers in the detection, monitoring and management of invasive alien lionfish. Management of Biological Invasions, 8(4): 589-598. DOI: https://doi.org/10.3391/ mbi.2017.8.4.14

August, T, Harvey, M, Lightfoot, P, Kilbey, D, Papadopoulos, T and Jepson, P. 2015. Emerging technologies for biological recording. Biological Journal of the Linnean Society, 115: 731-749. DOI: https:/ / doi.org/10.1111/bij.12534

Augustin, S, Boonham, N, De Kogel, WJ, Donner, P, Faccoli, M, Lees, DC, Marini, L, Mori, N, Toffolo, EP, Quilici, S, Roques, A, Yart, A and Battisti, A. 2012. A review of pest surveillance techniques for detecting quarantine pests in Europe. EPPO Bulletin, 42: 515551. DOI: https://doi.org/10.1111/epp.2600

Baghramian, M, Capaccioli, M, de Rijcke, S, Drotner, K, Dubertret, L, Irwin, A, Luty, T, Makarow, M, Moberg, C, Morega, AM and Owens, SE. 2019. Making sense of science for policy under conditions of complexity and uncertainty. Berlin: SAPEA. DOI: https://doi.org/10.26356/MASOS

Bellard, C, Cassey, P and Blackburn, TM. 2016. Alien species as a driver of recent extinctions. Biology Letters, 12: 20150623. DOI: https://doi.org/10.1098/ rsbl.2015.0623

Boakes, EH, McGowan, PJK, Fuller, RA, Chang-qing, D, Clark, NE, O'Connor, K and Mace, GM. 2010. Distorted views of biodiversity: Spatial and temporal bias in species occurrence data. PLoS Biology, 8(6): e1000385. DOI: https://doi.org/10.1371/journal. pbio. 1000385

Bonney, R, Ballard, H, Jordan, R, McCallie, E, Phillips, T, Shirk, J and Wilderman, CC. 2009. Public Participation in Scientific Research: Defining the Field and Assessing Its Potential for Informal Science Education - a CAISE Inquiry Group Report. Washington, DC: Center for Advancement of Informal Science Education.

Bradshaw, CJA, Leroy, B, Bellard, C, Roiz, D, Albert, C, Fournier, A, Barbet-Massin, M, Salles, J-M, Simard, F and Courchamp, F. 2016. Massive yet grossly underestimated global costs of invasive insects. Nature Communications, 7: 12986. DOI: https://doi.org/10.1038/ ncomms 12986
Caffrey, JM, Baars, JR, Barbour, JH, Boets, P, Boon, P, Davenport, K, Dick, JTA, Early, J, Edsman, L, Gallagher, C, Gross, J, Heinimaa, P, Horrill, C, Hudin, S and MacIssac, HJ. 2014. Tackling invasive alien species in Europe: The top 20 issues. Management of Biological Invasions, 5(1): 1-20. DOI: https:// doi.org/10.3391/mbi.2014.5.1.01

Cardador, L, Carrete, M, Gallardo, B and Tella, JL. 2016. Combining trade data and niche modelling improves predictions of the origin and distribution of nonnative European populations of a globally invasive species. Journal of Biogeography, 43(5): 967-978. DOI: https://doi.org/10.1111/jbi.12694

Chandler, M, See, L, Copas, K, Bonde, AM, López, BC, Danielsen, F, Legind, JK, Masinde, S, Miller-Rushing, AJ, Newman, G, Rosemartin, A and Turak, E. 2017. Contribution of citizen science towards international biodiversity monitoring. Biological Conservation, 213: 280-294. DOI: https://doi.org/10.1016/j.biocon.2016.09.004

Clavero, M, Brotons, L, Pons, P and Sol, D. 2009. Prominent role of invasive species in avian biodiversity loss. Biological Conservation, 142(10): 2043-2049. DOI: https://doi.org/10.1016/j.biocon.2009.03.034

Costello, MJ, Michener, WK, Gahegan, M, Zhang, Z-Q and Bourne, PE. 2013. Biodiversity data should be published, cited, and peer reviewed. Trends in Ecology \& Evolution, 28(8): 454-461. DOI: https://doi. org/10.1016/j.tree.2013.05.002

Crall, AW, Newman, GJ, Stohlgren, TJ, Holfelder, KA, Graham, J and Waller, DM. 2011. Assessing citizen science data quality: an invasive species case study. Conservation Letters, 4(6): 433-442. DOI: https://doi. org/10.1111/j.1755-263X.2011.00196.X

Crall, AW, Renz, M, Panke, BJ, Newman, GJ, Chapin, C, Graham, J and Bargeron, C. 2012. Developing costeffective early detection networks for regional invasions. Biological Invasions, 14(12): 2461-2469. DOI: https://doi.org/10.1007/s10530-012-0256-3

D'hondt, B, Vanderhoeven, S, Roelandt, S, Mayer, F, Versteirt, V, Adriaens, T, Ducheyne, E, San Martin, G, Grégoire, J-C, Stiers, I, Quoilin, S, Cigar, J, Heughebaert, A and Branquart, E. 2015. Harmonia + and Pandora + : risk screening tools for potentially invasive plants, animals and their pathogens. Biological Invasions, 1-15. DOI: https://doi.org/10.1007/ s10530-015-0843-1

Dickinson, JL, Shirk, J, Bonter, D, Bonney, R, Crain, RL, Martin, J, Phillips, T and Purcell, K. 2012. The current state of citizen science as a tool for ecological research and public engagement. Frontiers in Ecology and the Environment, 10(6): 291-297. DOI: https://doi. org/10.1890/110236

Dickinson, JL, Zuckerberg, B and Bonter, DN. 2010. Citizen science as an ecological research tool: Challenges and benefits. Annual Review of Ecology, Evolution, and Systematics, 41(1): 149-172. DOI: https:// doi.org/10.1146/annurev-ecolsys-102209-144636

Early, R, Bradley, BA, Dukes, JS, Lawler, JJ, Olden, JD, Blumenthal, DM, Gonzalez, P, Grosholz, ED, 
Ibañez, I, Miller, LP, Sorte, CJB and Tatem, AJ. 2016. Global threats from invasive alien species in the twenty-first century and national response capacities. Nature Communications, 7(1): 12485. DOI: https://doi. org/10.1038/ncomms 12485

Easterbrook, SM. 2014. Open code for open science? Nature Geoscience, 7: 779. DOI: https://doi. org/10.1038/ngeo2283

eBird. (2018). Global Big Day 2018: a birding world record. Available at https://ebird.org/colombia/news/globalbig-day-2018-a-birding-world-record [Last Accessed 23 February 2019].

Essl, F, Bacher, S, Blackburn, TM, Booy, O, Brundu, G, Brunel, S, Cardoso, A-C, Eschen, R, Gallardo, B, Galil, B, García-Berthou, E, Genovesi, P, Groom, Q, Harrower, C, Hulme, PE, Katsanevakis, S, Kenis, M, Kühn, I, Kumschick, S, Martinou, AF, Nentwig, W, O'Flynn, C, Pagad, S, Pergl, J, Pyšek, P, Rabitsch, W, Richardson, DM, Roques, A, Roy, HE, Scalera, R, Schindler, S, Seebens, H, Vanderhoeven, S, Vilà, M, Wilson, JRU, Zenetos, A and Jeschke, JM. 2015. Crossing Frontiers in Tackling Pathways of Biological Invasions. BioScience, 65(8): 769-782. DOI: https:// doi.org/10.1093/biosci/biv082

Essl, F, Dullinger, S, Rabitsch, W, Hulme, PE, Hülber, K, Jarošík, V, Kleinbauer, I, Krausmann, F, Kühn, I, Nentwig, W, Vilà, M, Genovesi, P, Gherardi, F, Desprez-Loustau, M-L, Roques, A and Pyšek, P. 2010. Socioeconomic legacy yields an invasion debt, Proceedings of the National Academy of Sciences, 108(1): 203207. DOI: https://doi.org/10.1073/pnas.1011728108

Ferreira, MR, Proenca, JF and Proenca, T. 2009. Motivations and management factors of volunteer work in nonprofit organisations: a literature review. In 8th International Congress of the International Association on Public and Nonprofit Marketing.

Figueiredo Nascimento, S, Cuccillato, E, Schade, S and Guimarães Pereira, A. 2016. Citizen Engagement in Science and Policy Making, EUR 28328 EN, DOI: https://doi.org/10.2788/40563

Gallo, T and Waitt, D. 2011. Creating a successful citizen science model to detect and report invasive species. Bioscience, 61(6): 459-465. DOI: https://doi. org/10.1525/bio.2011.61.6.8

Geldmann, J, Heilmann-Clausen, J, Holm, TE, Levinsky, I, Markussen, B, Olsen, K, Rahbek, C and Tøttrup, AP. 2016. What determines spatial bias in citizen science? Exploring four recording schemes with different proficiency requirements. Diversity and Distributions, 22(11): 1139-1149. DOI: https://doi.org/10.1111/ddi.12477

Genovesi, P and Shine, C. 2004. European strategy on invasive alien species: Convention on the Conservation of European Wildlife and Habitats (Bern Convention) (No. 18-137), 1-66. Council of Europe.

Geoghegan, H, Dyke, A, Pateman, R, West, S and Everett, G. 2016. Understanding motivations for citizen science. Final report on behalf of UKEOF, University of Reading, Stockholm Environment Institute (University of York) and University of the West of England.
Giraud, C, Calenge, C, Coron, C and Julliard, R. 2016. Capitalizing on opportunistic data for monitoring relative abundances of species. Biometrics, 72(2): 649658. DOI: https://doi.org/10.1111/biom.12431

Grason, EW, McDonald, PS, Adams, J, Litle, K, Apple, JK and Pleus, A. 2018. Citizen science program detects range expansion of the globally invasive European green crab in Washington State (USA). Management of Biological Invasions, 9(1): 39-47. DOI: https://doi. org/10.3391/mbi.2018.9.1.04

Groom, QJ, Adriaens, T, Desmet, P, Simpson, A, Wever, AD, Bazos, I, Cardoso, AC, Charles, L, Christopoulou, A, Gazda, A, Helmisaari, H, Hobern, D, Josefsson, M, Lucy, F, Marisavljevic, D, Oszako, T, Pergl, J, Petrovic-Obradovic, O, Prévot, C, Ravn, HP, Richards, G, Roques, A, Roy, HE, Rozenberg, MAA, Scalera, R, Tricarico, E, Trichkova, T, Vercayie, D, Zenetos, A and Vanderhoeven, S. 2017b. Seven recommendations to make your invasive alien species data more useful. Frontiers in Applied Mathematics and Statistics, 3: 13. DOI: https://doi.org/10.3389/fams.2017.00013

Groom, QJ, Desmet, P, Vanderhoeven, S and Adriaens, T. 2015. The importance of open data for invasive alien species research, policy and management. Management of Biological Invasions, 6(2): 119-125. DOI: https://doi.org/10.3391/mbi.2015.6.2.02

Groom, QJ, Weatherdon, L and Geijzendorffer, IR. 2017. Is citizen science an open science in the case of biodiversity observations? Journal of Applied Ecology 54: 612-617. DOI: https://doi.org/10.1111/13652664.12767

Guerrini, CJ, Majumder, MA, Lewellyn, MJ and McGuire, AL. 2018. Citizen science, public policy. Science, 361: 134-136. DOI: https://doi.org/10.1126/science.aar8379

Hamer, SA, Curtis-Robles R and Hamer, GL. 2018. Contributions of citizen scientists to arthropod vector data in the age of digital epidemiology. Current Opinion in Insect Science, 28: 98-104. DOI: https://doi. org/10.1016/j.cois.2018.05.005

Hurlbert, AH and Liang, Z. 2012. Spatiotemporal Variation in Avian Migration Phenology: Citizen Science Reveals Effects of Climate Change. PLOS ONE, 7: e31662. DOI: https://doi.org/10.1371/journal. pone.0031662

IPBES. 2019. Global assessment report on biodiversity and ecosystem services, summary for policy-makers. Intergovernmental Science-Policy Platform on Biodiversity and Ecosystem Services.

Irwin, A. 2001. Constructing the scientific citizen: science and democracy in the biosciences. Public Understanding of Science, 10: 1-18. DOI: https://doi.org/10.3109/ a03685

Jarnevich, CS, Simpson, A, Graham, JJ, Newman, GJ and Bargeron, CT. 2015. Running a network on a shoestring: the Global Invasive Species Information Network. Management of Biological Invasions, 6: 137146. DOI: https://doi.org/10.3391/mbi.2015.6.2.04 
Kampen, H, Medlock, JM, Vaux, AG, Koenraadt, CJ, Van Vliet, AJ, Bartumeus, F, Oltra, A, Sousa, CA, Chouin, $\mathbf{S}$ and Werner, D. 2015. Approaches to passive mosquito surveillance in the EU. Parasites \& vectors, 8: 9. DOI: https://doi.org/10.1186/s13071-0140604-5

Katsanevakis, S, Deriu, I, D'Amico, F, Nunes, AL, Pelaez Sanchez, S, Crocetta, F, Arianoutsou, M, Bazos, I, Christopoulou, A and Curto. G. 2015. European alien species information network (EASIN): supporting European policies and scientific research. Management of Biological Invasions, 6(2): 147-157. DOI: https://doi. org/10.3391/mbi.2015.6.2.05

Knowler, D. 2005. Reassessing the costs of biological invasion: Mnemiopsis leidyi in the Black Sea. Ecological Economics, 52: 187-199. DOI: https://doi.org/10.1016/j. ecolecon.2004.06.013

Lagoze, C. 2014. eBird: Curating Citizen Science Data for Use by Diverse Communities. International Journal of Digital Curation, 9: 71-82. DOI: https://doi. org/10.2218/ijdc.v9i1.302

Leung, B, Lodge, DM, Finnoff, D, Shogren, JF, Lewis, MA and Lamberti, G. 2002. An ounce of prevention or a pound of cure: bioeconomic risk analysis of invasive species. Proceedings of the Royal Society of London. Series B: Biological Sciences, 269(1508): 2407-2413. DOI: https://doi.org/10.1098/rspb.2002.2179

Lucy, FE, Roy, H, Simpson, A, Carlton, JT, Hanson, JM and Magellan, $\mathbf{K}$, et al. 2016. INVASIVESNET towards an international association for open knowledge on invasive alien species. Management of Biological Invasions, 7(2): 131-139. DOI: https://doi.org/10.3391/ mbi.2016.7.2.01

McGeoch, MA, Butchart, SHM, Spear, D, Marais, E, Kleynhans, EJ, Symes, A, Chanson, J and Hoffmann, M. 2010. Global indicators of biological invasion: species numbers, biodiversity impact and policy responses: Invasive alien species indicator: 2010 Biodiversity Target. Diversity and Distributions, 16(1): 95-108. DOI: https://doi.org/10.1111/j.14724642.2009.00633.x

Myers, JH, Simberloff, D, Kuris, AM and Carey, JR. 2000. Eradication revisited: dealing with exotic species. Trends in Ecology \& Evolution, 15(8): 316-320. DOI: https://doi.org/10.1016/S0169-5347(00)01914-5

Novoa, AH, Kaplan, H, Wilson, JRU and Richardson, DM. 2016. Resolving a prickly situation: involving stakeholders in invasive cactus management in South Africa. Environmental Management, 57(5): 998-1008. DOI: https://doi.org/10.1007/s00267015-0645-3

Page, R. 2016. Towards a biodiversity knowledge graph. Research Ideas and Outcomes, 2: e8767. DOI: https:// doi.org/10.3897/rio.2.e8767

Palmer, JRB, Oltra, A, Collantes, F. Delgado, JA, Lucientes, J, Delacour, S, Bengoa, M, Eritja, R and Bartumeus, F. 2017. Citizen science provides a reliable and scalable tool to track disease-carrying mosquitoes. Nature communications, 8: 916. DOI: https://doi. org/10.1038/s41467-017-00914-9
Perring, FH and Walters, SM. 1962. Atlas of the British flora. Nelson, London and Edinburgh.

Pescott, OL, Walker, KJ, Pocock, MJ, Jitlal, M, Outhwaite, CL, Cheffings, CM, Harris, F and Roy, DB. 2015. Ecological monitoring with citizen science: the design and implementation of schemes for recording plants in Britain and Ireland. Biological Journal of the Linnean Society, 115: 505-521. DOI: https://doi. org/10.1111/bij.12581

Pocock, MJ, Roy, HE, Preston, CD and Roy, DB. 2015. The Biological Records Centre: a pioneer of citizen science. Biological Journal of the Linnean Society, 115(3): 475-493. DOI: https://doi.org/10.1111/bij.12548

Pratt, CF, Constantine, KL and Murphy, ST. 2017. Economic impacts of invasive alien species on African smallholder livelihoods. Global Food Security, 14: 31-37. DOI: https://doi.org/10.1016/j.gfs.2017.01.011

Robertson, T, Dring, M, Guralnick, R, Bloom, D, Wieczorek, J, Braak, K, Otegui, J, Russell, L and Desmet, P. 2014. The GBIF integrated publishing toolkit: Facilitating the efficient publishing of biodiversity data on the internet. PLOS ONE, 9(8): e102623. DOI: https://doi.org/10.1371/journal.pone.0102623

Rotman, D, Preece, J, Hammock, J, Procita, K, Hansen, D, Parr, C, Lewis, D and Jacobs, D. 2012. Dynamic changes in motivation in collaborative citizen-science projects. Proceedings of the ACM 2012 Conference on Computer Supported Cooperative Work, CSCW '12 (New York, NY: ACM), 217-226. DOI: https://doi. org/10.1145/2145204.2145238

Roy, H, Groom, Q, Adriaens, T, Agnello, G, Antic, M, Archambeau, A-S, Bacher, S, Bonn, A, Brown, P Brundu, G, et al. 2018. Increasing understanding of alien species through citizen science (Alien-CSI). Research Ideas and Outcomes, 4: e31412. DOI: https:// doi.org/10.3897/rio.4.e31412

Schade, S, Kotsev, A, Cardoso, AC, Tsiamis, K, Gervasini, E, Spinelli, F, Mitton, I and Sgnaolin, R. 2019. Aliens in Europe. An open approach to involve more people in invasive species detection. Computers, Environment and Urban Systems, 78: 101384. DOI: https:// doi.org/10.1016/j.compenvurbsys.2019.101384

Scyphers, SB, Powers, SP, Akins, JL, Drymon, JM, Martin, CW, Schobernd, ZH, Schofield, PJ, Shipp, RL and Switzer, TS. 2015. The role of citizens in detecting and responding to a rapid marine invasion. Conservation Letters, 8(4): 242-250. DOI: https://doi. org/10.1111/conl.12127

Seebens, H, Blackburn, TM, Dyer, EE, Genovesi, P, Hulme, PE, Jeschke, JM, Pagad, S, Pyšek, P, Winter, M, Arianoutsou, M, Bacher, S, Blasius, B, Brundu, G, Capinha, C, Celesti-Grapow, L, Dawson, W, Dullinger, S, Fuentes, N, Jäger, H, Kartesz, J, Kenis, M, Kreft, H, Kühn, I, Lenzner, B, Liebhold, A, Mosena, A, Moser, D, Nishino, M, Pearman, D, Pergl, J, Rabitsch, W, Rojas-Sandoval, J, Roques, A, Rorke, S, Rossinelli, S, Roy, HE, Scalera, R, Schindler, S, Štajerová, K, Tokarska-Guzik, B, van Kleunen, M, Walker, K, Weigelt, P, Yamanaka, T and Essl, F. 2017. No saturation in the accumulation 
of alien species worldwide. Nature Communications, 8: 14435. DOI: https://doi.org/10.1038/ncomms 14435

Senabre, E, Ferran Ferrer, N and Perelló, J. 2018. Participatory design of citizen science experiments. Comunicar, 26(54): 29-38. DOI: https://doi.org/10.3916/ C54-2018-03

Shackleton, RT, Adriaens, T, Brundu, G, DehnenSchmutz, K, Estévez, RA, Fried, J, Larson, BM, Liu, S, Marchante, E and Marchante, H. 2019. Stakeholder engagement in the study and management of invasive alien species. Journal of Environmental Management, 229: 88-101. DOI: https://doi.org/10.1016/j.jenvman.2018.04.044

Shirk, JL, Ballard, HL, Wilderman, CC, Phillips, T, Wiggins, A, Jordan, R, McCallie, E, Minarchek, M, Lewenstein, BV, Krasny, ME and Bonney R. 2012. Public participation in scientific research: a framework for deliberate design. Ecology and Society, 17: 29. DOI: https://doi.org/10.5751/ES-04705-170229

Silvertown, J. 2009. A new dawn for citizen science. Trends in Ecology \& Evolution, 24(9): 467-471. DOI: https://doi.org/10.1016/j.tree.2009.03.017

Simberloff, D, Parker, IM and Windle, PN. 2005. Introduced species policy, management, and future research needs, Frontiers in Ecology and the Environment, 3(1): 12-20. DOI: https://doi.org/10.1890/15409295(2005)003[0012:ISPMAF]2.0.CO;2

Smith, B and Tibbles, J. 1980. Sea lamprey (Petromyzon marinus) in Lakes Huron, Michigan, and Superior: history of invasion and control, 1936-78. Canadian Journal of Fisheries and Aquatic Sciences, 37: 1780-1801. DOI: https://doi.org/10.1139/f80-222

Smith, M, Cecchi, L, Skjøth, CA, Karrer, G and Šikoparija, B. 2013. Common ragweed: A threat to environmental health in Europe. Environment International, 61: 115-126. DOI: https://doi.org/10.1016/j. envint.2013.08.005

Stodden, V, Guo, P and Ma, Z. 2013. Toward reproducible computational research: an empirical analysis of data and code policy adoption by journals. PLOS one, 8: e67111. DOI: https://doi.org/10.1371/journal. pone.0067111

Sullivan, BL, Aycrigg, JL, Barry, JH, Bonney, RE, Bruns, N, Cooper, CB, Damoulas, T, Dhondt, AA, Dietterich, T, Farnsworth, A and Fink, D. 2014. The eBird enterprise: an integrated approach to development and application of citizen science. Biological Conservation, 169: 31-40. DOI: https://doi.org/10.1016/j. biocon.2013.11.003

Theobald, EJ, Ettinger, AK, Burgess, HK, DeBey, LB, Schmidt, NR, Froehlich, HE, Wagner, C, Hille Ris Lambers, J, Tewksbury, J, Harsch, MA and Parrish, JK. 2015. Global change and local solutions: Tapping the unrealized potential of citizen science for biodiversity research. Biological Conservation, 181: 236-244. DOI: https://doi.org/10.1016/j.biocon.2014.10.021

Tollington, S, Turbé, A, Rabitsch, W, Groombridge, JJ, Scalera, R, Essl, F and Shwartz, A. 2017. Making the EU Legislation on Invasive Species a Conservation Success: Invasive alien species policy in Europe. Conservation Letters, 10(1): 112-120. DOI: https://doi. org/10.1111/conl.12214

Vall-llosera, M, Woolnough, AP, Anderson, D and Cassey P. 2017. Improved surveillance for early detection of a potential invasive species: the alien Roseringed parakeet. Psittacula krameri in Australia. Biological Invasions, 19(4): 1273-1284. DOI: https://doi. org/10.1007/s10530-016-1332-x

Vanderhoeven, S, Adriaens, T, Desmet, P, Strubbe, D, Backeljau, T, Barbier, Y, Brosens, D, Cigar, J, Coupremanne, M, De Troch, R, Eggermont, H, Heughebaert, A, Hostens, K, Huybrechts, P, Jacquemart, A-L, Lens, L, Monty, A, Paquet, J-Y, Prévot, C, Robertson, T, Termonia, P, Van De Kerchove, R, Van Hoey, G, Van Schaeybroeck, B, Vercayie, D, Verleye, T, Welby, S and Groom, Q. 2017. Tracking invasive alien species (TrIAS): Building a data-driven framework to inform policy. Research Ideas and Outcomes, 3: e13414. DOI: https://doi. org/10.3897/rio.3.e13414

Vanderhoeven, S, Adriaens, T, D'hondt, B, Van Gossum, H, Vandegehuchte, M, Verreycken, $H_{\text {, }}$ Cigar, J and Branquart, E. 2015. A science-based approach to tackle invasive alien species in Belgiumthe role of the ISEIA protocol and the Harmonia information system as decision support tools. Management of Biological Invasions, 6(2): 197-208. DOI: https:// doi.org/10.3391/mbi.2015.6.2.10

Wallace, RD, Bargeron, CT, Moorhead, DJ and LaForest, JH. 2016. IveGot1: reporting and tracking invasive species in Florida. Southeastern Naturalist, 15(8): 51-63. DOI: https://doi.org/10.1656/058.01 5.sp805

Wetzel, FT, Bingham, HC, Groom, Q, Haase, P, Kõljalg, U, Kuhlmann, M, Martin, CS, Penev, L, Robertson, T, Saarenmaa, H and Schmeller, DS. 2018. Unlocking biodiversity data: Prioritization and filling the gaps in biodiversity observation data in Europe. Biological conservation, 221: 78-85. DOI: https://doi.org/10.1016/j. biocon.2017.12.024

Wilkinson, MD, Dumontier, M, Aalbersberg, IJ, Appleton, G, Axton, M, Baak, A, Blomberg, N, Boiten, JW, da Silva Santos, LB, Bourne, PE and Bouwman, J. 2016. The FAIR Guiding Principles for scientific data management and stewardship. Scientific data, 3. DOI: https://doi.org/10.1038/sdata.2016.18

Wittenberg, R and Cock, MJ. (eds.). 2001. Invasive alien species: a toolkit of best prevention and management practices. Wallingford, the United Kingdom: GISP/CAB International. DOI: https://doi. org/10.1079/9780851995694.0000

Woolley, AW, Chabris, CF, Pentland, A, Hashmi, N and Malone, TW. 2010. Evidence for a collective intelligence factor in the performance of human groups. Science, 330(6004): 686-688. DOI: https://doi. org/10.1126/science. 1193147 
How to cite this article: Groom, Q, Strubbe, D, Adriaens, T, Davis, AJS, Desmet, P, Oldoni, D, Reyserhove, L, Roy, HE and Vanderhoeven, S. 2019. Empowering Citizens to Inform Decision-Making as a Way Forward to Support Invasive Alien Species Policy. Citizen Science: Theory and Practice, 4(1): 33, pp.1-11. DOl: https://doi.org/10.5334/cstp.238

Submitted: 23 February 2019 Accepted: 24 October 2019 Published: 02 December 2019

Copyright: ๑ 2019 The Author(s). This is an open-access article distributed under the terms of the Creative Commons Attribution 4.0 International License (CC-BY 4.0), which permits unrestricted use, distribution, and reproduction in any medium, provided the original author and source are credited. See https://creativecommons.org/licenses/by/4.0/.

] $\mathbf{u}[\quad$ Citizen Science: Theory and Practice is a peer-reviewed open access journal published by Ubiquity Press. 